\title{
Study on Architectonics of Cultural Medium
}

\author{
Violetta Evallyo \\ State Institute for Art Studies (SIAS) \\ Moscow, Russia \\ E-mail: amaris_evally@mail.ru
}

\begin{abstract}
Screens and multimedia installations are widely used in various spheres of culture: from exhibition grounds and virtual museum guides to entertainment projects. Multimedia projects are, in fact, the leading genre of media industry in the socio-cultural environment. First of all, these are immersive performances, multimedia and virtual exhibitions, installations, interactive presentations and performances, virtual (and partially virtual) products. All of them differ not only in the way of constructing the media environment, but in the extent to which the viewer is involved in the media space. The article considers the most typical species of multimedia projects and their specifics.
\end{abstract}

Keywords—visual culture; split screen; multimedia; digital art; immersive; interactivity; virtuality

\section{INTRODUCTION}

The transition from the 20th to the 21st century was marked by a significant cultural shift, and also by a number of breakthroughs in the sphere of scientific and technological progress. The development of energy, industrial and, what is most important in the cultural aspect - information technology - has had the same effect on the way of life of the whole global community, like the discovery of fire, wheels, steam engine, electricity.

The way of life of the mankind has changed fundamentally; scale digitalization of many aspects of human life, the widespread introduction of "smart" technologies and devices has transformed everyday reality into an endless canvas for the representation of art objects. In practice, this is often realized in compliance with key principles of splitscreen. The eye of modern man practically works in simultaneous mode, perceiving the "video" of objective reality, smartphone screen, LED displays of billboards and other screen surfaces. Objective reality becomes a transit zone for individuals who are ready at any moment to "connect" into any other virtual reality.

Everywhere there is a split-screen effect which is mean fragmentation of the space of objective reality into various "subspaces". A split-screen represents a map of sociocultural space with its portals, and multimedia technologies are designed to limit the attention of the recipient to a specific location.

At the same time, a key concept for art - an environment - was transformed. As noted by L. Manovich, "if the traditional typology was based on difference in materials used in art practice, the new mediums either allowed for the use of different materials in arbitrary combinations (installation), or, even worse, aimed to dematerialize the art object (conceptual art)" [1].

So, we can indenify a medium which is formed in sociocultural space as a multimedia's one. In essence, the definition of "multimedia" literally means "a lot of mediums". Breaking the myths about this concept, A.A. Denikin defines it as "digital multimedia, the functionality of which is conditioned by computer technology, and the inclusion in the multimedia structure of the project / product / video product, audio, text and graphic information is accompanied by special software algorithms for user control of this information (interactivity)" [2]. A multimedia product and its multi-medium is the consequence of purposeful actions, while an effect of split-screen is formed more spontaneously.

One of the key properties of multimedia is considered interactivity, immersion, virtuality. So we'll try to find the interrelation between it and a socio-cultural medium.

\section{INTERACTIVITY}

Interactivity is the ability of an object (program, resource, etc.) to interact with its user [3]. In more detailed consideration, interactivity manifests the ability to identify the interrelation between a person and objects within any environment. So, "interactivity is a relationship in which the actions and behaviours of people and/or objects are codeterminate" [4]. However, interactivity isn't a product of modern technology, because the pageant culture of ancient periods in most cases implies the interaction of performers and recipients, or at all didn't have gradations for performers and spectators.

Further we'll consider several examples of interactive multimedia productions. So, the main feature of interactive installations is that the viewer directly affects on a space images are generated interactively depending on the movement of objects. For example, in the panoramic video installation "Quantum Space" (Kuflex, The MARS Center for Contemporary Art, Moscow, 2015), the viewer, in fact, dissolves in the universe, decaying into quanta of light. In the earlier project Abstract Wall (Kuflex, Garage Museum of Contemporary Art, Moscow, 2013) visitor's silhouettes and movements were projected onto the screen as a picture of abstractionists. Thus, a visitor of such interactive installations realizes a requirement to leave his trace in the universe. On the other hand he is temporarily given the 
function of a deity with the ability to influence and transform matter, even virtual.

Another facet of interactivity (especially against the backdrop of the virtualization of the socio-cultural medium) is the ever-growing interest in body. The question of the role of corporeality is raised in many studies of new media, both dedicated to computer games, digital art, and private multimedia projects. T. Friedman believes that "the constant interactivity in a simulation game - the perpetual feedback between a player's choice, the computer's almost instantaneous response, the player's response to that response, and so on - is a cybernetic loop, in which the line demarcating the end of the player's consciousness and the beginning of the computer's world blurs" [5]. However, we are closer to Hansen's thesis that "there is no information (or image) in the absence of the form-giving potential of human embodiment" [6]. But it is necessary to introduce some clarifications. In our opinion, interactivity is a reflection of the requirement of a person who surrounded by products of technological progress, to control the processes that are associated with these products, interact with them. And this need is fully realized by interactive installations and performances.

\section{IMMERSION}

The modern multimedia environment is not limited to interactivity; it's characterized by a several criterias, among which, in our opinion, the key ones are also immersion and virtuality. Immersion is characterized by the effect of dipping the recipient literally inside the object of representation. The increasing requirement of immersion is characterized by a general trend of cultural demassification and the restructuring of cultural schemes [7]. Thus, the urgency of transforming cultural phenomena into a "niche" product increases. The refusal of massiveness is generated by the requirement to limit and filter information flows. So, a paradox arises in the sociocultural environment: multimedia products become relevant and demand, if they are creating the effect of exclusivity and, moreover, a personal "approach". This problem is solved with immersion: the recipient is dipped actually inside the work of art, inside himself, into the space of the play, etc.

Nowaday, the character's movements in the plot and the next following him audience, we can see in the immersive performances. For example, the collective work of the directors Victor Karin and Mia Zanetti — "The Revenants" (based on the play of G. Ibsen "Ghosts"). Each of the 50 rooms of the Dashkov mansion has its own action. Spectators whose faces are covered with masks are free in their movements. Gray masks that do not have holes for the mouth are making the viewer a participant in the action, giving them the role of a faceless crowd of ghosts. Curiosity forces the viewer to follow the characters from room to room. In the play we can see tendencies of modern massculture: to give the viewer a unique impression of the consumption of a personal product. As E.V. Vasenina observes, "in the performance-attraction the viewer is not chained to the chair, chooses his route within the preset space and receives a personal performance, as the point of view of what is happening every minute formed individually" [8]. But also the traditions of the medieval theater are strong.

The first stages in the Middle Ages were not specially built scaffolding, but any area free for demonstration. The liturgical texts were staged by clergymen first in the church, then on the church-porch. In the XII-XIII centuries, religious performances had completely come out of the interior of the temples and requirement to recreate the appropriate situation on the square scaffold arised. The Mysteries had required scenery from specific places of action, so several types of simultaneous scenes appeared. First it was a mobile cart (simple or two-tier vans). Each cart was intended to display a separate episode, after which the cart was leaving for the next group of spectators, and another one came to replace it [9].

I.V. Klimova turns attention to the fact that "the simultaneous scene reflects the medieval model of the world order in its own way: the vertical, that was located within the boundaries of the mystery performance, was arranged on the square horizontally" [10]. An important aspect is the problem of overcoming distances - it was enough for the hero to take several steps to change the "location". The audience followed the characters from one scene to another. Often in the space of the mystery scene, the action acquired a simultaneous character: it occurred in two or more places simultaneously. Thus, modern immersive performances revive the culture of the medieval performance.

Modern multimedia exhibitions are designed to immerse the viewer, in fact, inside the work of art. Artifacts are projected onto canvases, allowing for detailed study of the image (for example, multimedia exhibitions in Artplay, Moscow: Van Gogh, Revived Canvases 2.0, 2015; From Monet to Cezanne, French Impressionists, 2015; From Monet to Malevich. The great Modernists", 2017, etc.). Such exhibitions correspond to the definition of multimedia: they are accompanied by music creating an atmosphere is different from the familiar medium of the museum, by explaining inscriptions and comments or excursion stories. In connection with this, Fr. Penz perceive museums as "laboratories of change, as the technological/digital layer cuts across all the other narrative layers; the interactive screens are embodied in the architecture as modern artifacts, the audioguides help to convey both the curatorial narrative and the stories of the artifacts" [11].

Besides the immersion, the fragmentary of the art's canvas and the "phenomenon of aesthetic prominence" [12] arise. On each separate screen, a part of the picture is projected, thus acquiring potential independence and a hyperlink function in relation to other fragments. L. Manovitch notes that "The very principle of hyperlinking, which forms the basis of much of interactive media, objectifies the process of association often taken to be central to human thinking. Mental processes of reflection, problem solving, recall and association are externalized, equated with following a link, moving to a new page, choosing a new image, or a new scene. Before we would look at an image and mentally follow our own private associations to other images" [13]. 
In the modern culture fragmentation is exposed to artifacts, but a person is exposed too. I.A. Malkovskaya notes that "universal communizability (permeability for communication) of social, political, information spaces makes communication a prerogative not so much of the human world as of the socio-technological information universe with respect to which a person with his innate communication skills acts as a function, then as an object, then as an attribute, as a client, as an electorate, as a user. In all cases, a person will be claimed only partially, depending on which "fragment" communication is needed today" [14].

Thus, immersion is the most popular type of multimedia presentation due to its understandability and "individuality in approach", but also one of the most difficult from the ideological point of view. Fragmentation of the performance, cultural artifact leads the inevitable loss of segments from the overall picture and the impossibility of forming integrity.

The main task facing the creators of multimedia installations is nessesary to create the effect of maximum inclusion of the viewer in the projected space, to place him "inside" the broadcast world. For example, an installation in Moskvarium immerses the viewer in the underwater world. On a lot number of screens (from all sides), the sea depth is projected, on which the sharks are in charge. The extent of involvement of the viewer is low, but the undemanding viewer can quite "tickle the nerves" with applying of imagination. Installation "Outside the Window" (Svishchev M., Svibovich A., Letzius A.) is immersing the viewer inside some mechanism, gradually and visually, and through music transforming the enclosed space into lightness and freedom pouring light from the window.

The main purpose of such multimedia installations is to immerse the viewer in the image space and try to evoke special emotions. This effect was typical for the first Lumiere's performances, when the audience literally left the auditorium in a panic, for fear of perishing under the wheels of the arriving train. But if the first cinematographers had tried to convince people of the unreality of the show, modern visual culture is dictates the opposite requirements. The main specific of such installations is that the visitor remains only an observer.

An important place in the media environment is occupied by immersive performances that dip a person inside himself as figuratively ("I am excitement and stranger", The MARS Center for Contemporary Art, Moscow, 2018), and literally (Into Yourself - Fall, A. Kapoor, Gothenburg, 2017.). Accordint to E.V. Nikolaeva report at the conference "Immersive performances: an aestetic experiance of behind the screen" concludes that such representations, in fact, is a reflection on the human body, the entrance into the body is virtual. Nevertheless, there is a reverse process of accentuation on its reality, on sensations [15], the question of "body" and the prevalence of "real" sensations over virtual ones is raised again.

\section{VIRTUALITY}

If the traditions of immersion and interactivity go back to the epochs preceding the digital one, then visualizing the possibilities of virtuality (but not the ideology itself, which, as we know, goes back to medieval discourse [16]) is fully correlated with the present. Thus, the American researcher K. Hayles notes that "the thirty million Americans who are plugged into the Internet increasingly engage in virtual experiences enacting a division between the material body that exits on one side of the screen and the computer simulacra that seem to create a space inside the screen" [17].

In a global sense, not only user identity is virtualized, but, as I.I. Yugay notes that the area of virtual artistic culture is being formed; in other words this is "a total combination of genres that can dip the viewer in a conceptually new space of a product with the aid of simulation and interactivity, which are based on technical mediums" [18].

So, virtual exhibitions are designed to immerse the visitor directly inside the depicted world (usually with the help of vr-helmet technology). For example, "Night at the Library" (R. Lepage, Multimedia Art Museum, 2017) invites to a virtual journey through the libraries of the world, both real and imaginary. According to the creator, he "wanted to try to convey this sense of the change of cultures that you experience when you visit different libraries of the world without pausing because of flights, without spending time searching" [19]. In a virtual journey "The Hermitage. The immersion in the history" (Hermitage, St. Petersburg) a visitor is accompained by $\mathrm{K}$. Khabensky like Virgil in the immortal work "The Divine Comedy". But as Dante, every visitor is only an observer and can't influence at the virtual world of the museum in any way.

In the context of a comparison with split-screen as spontaneously forming environment, which has a lot of portals, virtuality, in fact, is that closed space, purposefully "cut off" from the context of objective reality. The user / consumer doesn't have the ability to connect to any other screen surfaces, at his disposal is only one space, simulated by himself or a director. Immersed in a virtual environment, an individual not only gets personal leisure, but also can immerse himself in the process offered by the creators of a virtual product.

Concerning the processuality of new media, a remark is made by the philosopher M. Hansen: "media convergence under digitality actually increases the centrality of the body as framer of information: as media lose their material specificity, the body takes on a more prominent function as selective processor in the creation of images. The digital image on a computer screen is no longer the same object as the photograph it may digitally simulate. In contrast to this static object, the digital image involves a processing of data, the constant refreshing of the interpretation of that data through an interface projected on the screen at a frame rate that makes it appear static, but this image is in fact highly dynamic, capable of being modified at any moment. The digital image is processual" [20].

Virtual products demands modern sociocultural environment. Probably, their popularity is justified, on the one hand, by curiosity in relation to the degree of development and possibility of a technology. On other hand in this way requirements about to get into an environment 
that does not let portals and windows into "outside" environments into their space is realized. That is, a person, in addition to new experience, can also get rest from simultaneous streams of information, images that surround him everywhere in objective reality.

\section{CONCLUSION}

The study in the field of digital anthropology rightly states that modern multimedia products, "digital projects continue the foundational work of museums more generally - to create a sense of public, to draw in community and engage community with broader educative, expressive and experiential ideas about knowing things through things" [21].

Nowdays, the principles of the structure of the sociocultural environment have obviously changed. As L. Manovitch rightly notes,"we are increasingly "interfacing" to predominantly cultural data: texts, photographs, films, music, virtual environments. In short, we are no longer interfacing to a computer but to culture encoded in digital form" [22]. And this becomes an adequate response to the active development of technology. The sphere of art and its representation absorbe these tendencies. At the same time, along with the "classical" exposure, this sphere is using multimedia technologies as the familiar and convenient way of "high" art representation. Among other main criteria of modern multimedia, in our view, are interactivity, immersion and virtuality. Interactivity is directly related with the processuality whitch is the main trend of modern digital art and ways of representing classical art. Thus, the consumer of a cultural product becomes a witness and in some cases a coauthor of a cultural artifact.

Immersion is one of the oldest "techniques" of the representation of an art, but today it is the most relevant. Due to the oversaturation of the modern socio-cultural environment with screens and other translating projections that play the role of portals in the realm of other "realities" and meanings, compulsory space restriction on one hand allows one to "rest" from the usual reality. On the other side, it actualizes the tendency of the representation of an individual product that has not only a certain level of uniqueness, but also personification. But as a consequence, the tendency of fragmentation, both the personality of consumers and the work of art, is growing.

Achieved high-level technical equipment makes possible to use virtuality as an exciting cultural product. Multimedium of the socio-cultural environment, and in connection with this - the limited area of private space also increases the demand for virtuality. One of the leading themes of virtualized products is the immersion of the subject in the environment of a cultural object (virtual tours) and the main feature is the limited nature of the space represented, its finiteness. The second trend can be defined as the journey of the consumer into himself, both metaphysically and literally. The demand for such cultural products is directly related to human's body and its partial "loss" in the modern technological socio-cultural space.

\section{REFERENCES}

[1] Manovich Post-media esthetics $\mathrm{M}$, entrum $\mathrm{f} \mathrm{r}$ unst und Medientechnologie (ed.). DisLocations, 2001. URL: $\mathrm{http}: / /$ manovich.net/content/04-projects/029-post-mediaaesthetics/29_article_2001.pdf.

[2] A. A. Denikin. Multimedia and art: from myths to realities. Moscow, SIAS, Art culture, No. 3, $2014 . \quad$ URL: http://sias.ru/publications/magazines/kultura/2014-3/yazyki/843.html.

[3] O. V. Shlykova. Culture of multimedia. Textbook for students / MGIK. Moscow: FAIR-PRESS, 2004 P 10

[4] Dewdney A., Ride P. The New Media. Handbook. USA and Canada: Routledge, 2006 P 213

[5] Friedman T. Civilization and its discontents: Simulation, subjectivity, and space // G. Smith (Ed.), Discovering discs: Transforming space and place on CD-ROM New York, 1999 P 137

[6] Hansen M B N New Philosophy for New Media ondon, $2004 \mathrm{Pp}$ Xxi, 50.

[7] Yu. V. Strakovich. Modern civilization: the demassification of artistic demand. Moscow, SIAS, Art culture, No. 2 (18), 2016. URL: $\mathrm{http}: / /$ sias.ru/publications/magazines/kultura/2016-2-18/teoriyahudozhestvennoy-kultury/5040.html.

[8] E. V. Vasenina. The theater of participation: about the role of the "wandering body" of spectators and the choreography of plays"quests" Moscow, SIAS, Art culture, No. 2 (18). 2016. URL: http://sias.ru/publications/magazines/kultura/2016-218/yazyki/5044.html.

[9] V. I. Berezkin. The art of the scenography of the world theater. T. 1: From the sources to the middle of the twentieth century. Ed. 2-nd, corrected. - Moscow: Publishing house LCI, 2011. Pp. 81-85.

[10] I. V. Klimova. Theatrical language of the mystery of the late Middle Ages (Germany, XV century.): Avtoref. dis. candidate of Art Studies: 17.00.01. - M , 2000

[11] Fr. Penz. Museums as Laboratories of Change: The Case for the Moving Image // Film, Art, New Media Museum Without Walls? // Ed by ngela Dalle Vacche P GR VE M CMI N, 2012 P 295.

[12] M. L. Gasparov. Philology as a morality. Moscow: Fortuna EL Publ., 2012. P. 110.

[13] Manovich L. The Language of New Media. The MIT Press Cambridge, Massachusetts ondon, England, 2001 P 61

[14] I. A. Malkovskaya. "Spectacular arena" of social practices. Moscow, SIAS, Art culture, No. 1 (19), 2017. URL: http://sias.ru/publications/magazines/kultura/2017-1-19/sotsialnayafilosofiya-i-sotsiologiya/5216.html.

[15] E.V. Nikolaeva "Immersive performances: an aestetic experiance of behind the screen"/ report at the conference "A screen and a spectacle", Moscow, SIAS. March, 28. 2018.

[16] V. A. Emelin. Virtual Reality and Simulacra // Postmodernism and Information Technology. Moscow, 1999. URL: http://emeline.narod.ru/virtual.htm.

[17] Hayles K. How we became porthuman. Virtual Bodies in Cybernetics, Literature and Informatics. The University of Chicago Press. Chicago, London, 1999. P. 20.

[18] Yugay I. I. Computer game as a form of artistic practice. // Izvestia. Herzen University. Saint Petersburg, 2007. No.37. C 367-368.

[19] A. Petrakova. Robert Lepage: "Only art, which will allow us to experience some experience, can force a modern person to leave the house" Moscow, The rt Newspaper Russia, October, 172017 Режим доступа: http://www.theartnewspaper.ru/posts/5014/.

[20] M Hansen New Philosophy for New Media ondon, 2004 P xxi

[21] Digital Anthropology // ed. by H.A. Horst and D. Miller. BERG Publ., London, New York, 2012. P. 281

[22] L. Manovich L. The Language of New Media. MIT Press, 2001. Pp. 69-70. 